\title{
CAN THE GAMBIA ECONOMY CATCH-UP WITH DEVELOPED ECONOMIES IN THE LONG-RUN?: A Time-Series Test of the Convergence Hypothesis and Endogenous Growth Model with Human Capital.
}

\author{
R. K. Ayeni, (Phd) \\ Department of Economics \\ School of Business and Public Administration \\ University of The Gambia
}

\begin{abstract}
This paper seeks to answer the question of how The Gambia economy can catch-up with developed economies. The convergence hypothesis implied by the Solow-type (1956) neoclassical model has been questioned by endogenous growth theories mainly in the context of a long-run growth path. One concept says convergence applies if poor economies tend to grow faster than the rich ones so that the poor tend to catch-up with the rich in terms of the level of per capita income. A recent research conducted by the Education Global Practice of The World Bank Group on the public expenditure review (PER) in the education sector in The Gambia made many recommendations on improving human capital development in the Gambia that need empirical clarifications. This paper provides an empirical and theoretical support and justification for the implementation of the recommendations. The paper conducted test of the convergence hypothesis using a series of Cobb-Douglas production models on Gambia using the U.S. economy as the base economy. Time series data on real GDP, Capital stock. Human capital stock and labor were collected for the period 1970 to 2016 . The study employed the classical least square regression after establishing the levels of integration of the variables. The study was able to establish that the Gambia economy has the tendency of "catch-up" with developed economy under the condition of improved and sustained human capital development. To achieve this, the paper lends credence to the recommendations of the PER that education budget should be increased in the medium to long term. Convergence may be observed for Gambia economies if it intensifies on subsidies for education, research and development.
\end{abstract}

Key Words: $\beta$-Convergence, Human capital, Endogenous growth, Education Public Expenditure, Return to scale.

JEL Classification: E

\section{INTRODUCTION}

Economic growth and convergence is one of the most discussed fields in economics, as longrun growth basically determines the welfare of countries. Sometimes it can be assumed that countries with lower GDP per capita tend to grow faster than the richer ones, this process is called catching-up. (Gaspar,2015). The Gambia has a small economy that relies primarily on tourism, rain-dependent agriculture, and remittances, and is vulnerable to external shocks. Real gross domestic product (GDP) growth was slightly above 3.5\% in 2017, propelled by lower interest rates and a rebound in the service sector. The fiscal situation, which deteriorated during the political crisis, has improved due to strengthen fiscal discipline and external support. Expenditure ceilings have helped control expenditures, and domestic revenues have recovered in 2017. (World Bank PER, 2017) 
The macroeconomic framework continues to be characterized by high debt levels, estimated at $123.6 \%$ of GDP in 2017, creating significant risks of debt distress. About $40 \%$ of the domestic debt is held by domestic banks, which poses risks for the stability of the banking sector.

The key long-term development challenges facing The Gambia are related to its undiversified economy, small internal market, limited access to resources, lack of skills necessary to build effective institutions, high population growth, lack of private sector job creation, and high rate of outmigration. Despite these macroeconomic conditions Gambia exchange rate rank among the best in Africa as one US Dollar is equivalent to about 47 Gambia Dalasi. This value is even better than exchange rate of Nigeria the so called giant of Africa.

In 2017 a research on The Public Expenditure Review (PER) in the education sector in The Gambia was conducted and the report prepared by the Education Global Practice of the World Bank Group. In the report, many recommendations were made on improving human capital development in the Gambia. This paper therefore serve as theoretical justification of the quick implementation of the PER recommendations. It aims at testing the convergence (catch-up) hypothesis linked with the endogenous growth theory campaign of human capital development as a major requirement for steady growth.

The paper is divided into nine sections. The next section after the introduction is the theoretical framework and literature review. This is followed by Model Specification and the Convergence Hypothesis Test. Section 4 presents the descriptive statistics of variables used in the model. Section 5 presents and discusses the empirical analysis of model. Section 6 conducts the testing of the convergence hypothesis. Section 7 discusses the role of human capital in relation to the convergence hypothesis. Section 8 presents a brief summary of the outlook of the Gambia education sector as reported by the PER. The last section concludes the study.

\section{THEORETICAL FRAMEWORK AND REVIEW OF LITERATURE}

Growth can be exogenous-based or endogenous-based. The endogenous growth model, a recent prominent economic growth theory, was developed by Romer (1986) and Lucas (1988) and it focused on the role of human capital from the outset as a main source of increasing returns and divergence in growth rates between developed and underdeveloped countries. The model was refined and extended further by Romer (1990), Rebelo (1991), and Stokey (1991).

In his own study, as an empirical test of the endogenous model, Barro (1991) initiated a test by regressing cross-country per capita income growth on a set of ancillary variables including the primary school enrollment ratio as a proxy variable for human capital. He found the initial level of human capital to be a significant determinant for economic growth. Kyriacou (1991) constructed a cross country human capital index from data on average school years in the labor force and school enrollment ratios. From the cross-country regression of per capita income growth, he finds the coefficient of initial human capital stock to be positive and significant but that of human capital growth to be negative and insignificant. However, Kyriacou's index is still another proxy variable limiting the validity of his empirical findings.

Ayeni (2018) conducted an empirical test of the endogenous growth model in a panel model. The paper provides an empirical test of the endogenous growth model in particular, the "Rival" human capital models of Romer (1990) and non-rival „idea“ models of Lucas (1988), for Africa economies using a panel of Africa data on human and knowledge capital stocks. The study employed two different Panel Cointegration techniques, the Panel ARDL (PMG) and the Fully Modified OLS on two aggregate production functions (knowledge capital based and human 
capital based models). The study was able to establish that the poor growth of Africa economies is not a woe but the result of poor and not sustained accumulation and use of human and knowledge capital. Convergence may be observed for African economies if they intensify on subsidies for education, research and development.

The convergence hypothesis implied by the Solow-type (1956) neoclassical model has been questioned by endogenous growth theories mainly in the context of a long-run growth path. Therefore, the hypothesis calls for an empirical test using time-series data rather than crosscountry data. There are two well-known concepts of convergence that appear in discussions of economic growth across countries or regions. One concept says convergence applies if poor economies tend to grow faster than the rich ones so that the poor tend to catch-up with the rich in terms of the level of per capita income. This type of catch-up or convergence is known as (beta) $\boldsymbol{\beta}$-convergence. Another concept concerns cross sectional dispersion. According to this concept convergence occurs if the dispersion, measured by the standard deviation of the logarithm of per capita income across a group of countries or regions, declines over time. This type of process is known as (sigma) $\sigma$-convergence.

In general the convergence of first type (poor countries grow faster than rich ones) is likely to generate convergence of second type (reduced dispersion of per capita income), but reduced dispersion of per capita income is not likely to generate conversion of this first type.

Furthermore the convergence process can be disturbed by new shocks that tend to increase dispersion. To model this convergence using time-series data, let us consider the following Cobb-Douglas specification:

$$
Y_{t}=A K_{t} L_{t} \ldots \ldots . .1 \quad 0<\alpha<\mathbf{1}, 0<\boldsymbol{\beta}<\mathbf{1},
$$

where $Y, K$ and $L$, are output, capital, and labor, respectively, and $\mathrm{A}$ is a technology factor (according to Solow). The conventional neoclassical production model assumes that $\boldsymbol{A}$ is exogenously determined and the law of diminishing marginal returns prevails. The convergence hypothesis implied by the model can be addressed by deriving the rate of return (r) as the difference between marginal product of capital and the depreciation rate (d)

$$
r=A K_{t}{ }^{1} L \quad d \ldots . . .2
$$

Assuming the growth rate of labor is exogenous and denoted as $\boldsymbol{n}$, the following condition must be satisfied to keep $\boldsymbol{r}$ at a constant level:

$$
\frac{d K / d t}{K}=\frac{n}{1} \ldots . .3
$$

This condition implies the steady state growth rate of capital stocks. If capital stocks are low relative to the population and, therefore, a higher rate of return prevails, then the growth rate of capital will be higher. As capital is accumulated, the rate of return will fall to the steady state level. In short, a developing economy with lower per capita capital stocks is expected to grow faster and to "converge" to the steady state achieved by advanced economies as proposed by Solow. 
In defining ' $\boldsymbol{A}$ ', the new growth theory, which focuses on the role of human capital, such as the first model in Lucas (1988), Stokey (1991), and Tamura (1991) proposed an endogenous technology factor as follows:

$$
A_{t}=B H_{t}^{c} \ldots . .4
$$

$\boldsymbol{H}$, is the level of human capital stocks; if $\boldsymbol{H}$, increases by $\mathbf{1}$ percent, $\mathbf{A}$, is assumed to increase by $\boldsymbol{c}$ percent. Now suppose that labor input is allocated between physical output production and human capital production by $\boldsymbol{x} \boldsymbol{L}$, and $(\mathbf{1}-\boldsymbol{x}) \boldsymbol{L}$, respectively. Then the production function of equation (1) can be respecified as

$$
Y_{t}=B H_{t}^{c} K_{t}\left(x L_{t}\right)
$$

In this model, endogenous growth is possible as long as there is continuous investment in human capital even if it keeps being accumulated. Assuming there is no diminishing return in the production of human capital; the assumption is embodied in the following form of the human capital production function. Growth of human capital is given as:

$$
\begin{aligned}
\frac{d H}{d t} & =j(1 \quad x) L_{t} \frac{H_{t}}{L_{t}} \quad \ldots . .6 \\
& =j(1 \quad x) H_{t}
\end{aligned}
$$

where $(\mathbf{1}-\boldsymbol{x}) \boldsymbol{L}$ is the labor input into the production of human capital and $\mathrm{j}$ is a productivity parameter. Productivity in human capital production is also assumed to be proportional to the level of per capita human capital stocks $(\mathbf{H} / \mathbf{L})$ at time $t$.

Both Romer (1990) and Rebelo (1991) have shown that sustained growth can be made compatible with technologies that display constant returns to scale by assuming that there are constant returns to factors that can be accumulated. If physical capital and human capital are such factors $(\alpha+\mathbf{c}=1)$, then non-converging growth is feasible.

Let us consider an alternative endogenous growth model which also departs from the assumption of exogenous technology factors but defines capital as total capital, which is the sum of physical capital and human capital. Let us specify the Cobb-Douglas function as

$$
Y_{t}=A_{t}\left(K_{t}+H_{t}\right) L_{t} \ldots . .7 \quad 0<\alpha<1, \quad 0<\beta<1
$$

Suppose the accumulation of total capital induces the accumulation of technology as follows:

$$
A_{t}=B\left(K_{t}+H_{t}\right)^{c} \ldots . .8
$$

Equation 8 assumes that 1 percent growth of total capital increases technology by c percent. The substitution of equation 8 into equation 7 gives

$$
Y_{t}=B\left(K_{t}+H_{t}\right)^{+c} L
$$

The rate of return to total capital is given by

$$
r=(+c) B\left(K_{t}+H_{t}\right)^{+c 1} L_{t} \quad d \ldots . .10
$$


If there is increasing returns to total capital $(\alpha+\mathbf{c}>$ l), the rate of return will increase as the capital stocks grow, as discussed in Romer (1986). This provides an explanation of why the convergence of growth rates among different economies is not universally observed, but it rules out the possibility of steady state equilibrium. Therefore, the later model of Romer (1990) and Rebelo (1991) assumes constant returns to total capital $(\alpha+c=1)$. Under the assumption of constant returns to capital, the rate of return will be given as constant regardless of the level of total capital stocks. In this case, the growth rate of total capital will also be constant and equal to the growth rate of per capita income. The economy is always at the steady state.

\section{MODEL SPECIFICATION AND THE CONVERGENCE HYPOTHESIS TEST}

From the theoretical review of endogenous growth models with human capital above and following Pyo(1995), the following equations are derived for estimation from the alternative Cobb-Douglas specifications of equations 1, 3, and 9:

$$
\begin{aligned}
& \log Y_{t}=+\log K_{t}+\log L_{t}+u_{t} \ldots \ldots \ldots 10 \\
& \log Y_{t}=+\log K_{t}+c \log H_{t}+\log \left(x L_{t}\right)+u_{t} \ldots \ldots 11 \\
& \log Y_{t}=+(+c) \log \left(K_{t}+H_{t}\right)+\log \left(x L_{t}\right)+u_{t} \ldots \ldots 12
\end{aligned}
$$

The test of convergence is sequential and comparative, Gambia economy was modeled and projected towards a developed economy as required by the Convergence hypothesis, here USA economy is chosen. The sequence of the test is as follows:

i. Equation 10 is needed to check the convergence hypothesis implied by the conventional neoclassical growth model. That is $(\boldsymbol{\alpha}+\boldsymbol{\beta}=1)$ holds using Gambia macroeconomic data.

ii. Equation 11 is the next, to test the statistical significance of the coefficient of human capital stocks $(\boldsymbol{H})$, and the hypothesis of constant returns to capital $(\boldsymbol{\alpha}+\boldsymbol{c}=\mathbf{1})$.

iii. We then proceed to test the same hypothesis $(a+c=1)$ from the estimation result of equation 12.

iv. If the hypothesis of constant returns to capital $(\boldsymbol{a}+\boldsymbol{c}=1)$ is accepted from the estimation results of equations 11 and 12 , it may be necessary to re-estimate equations 11 and 12 by imposing the linear constraint $\boldsymbol{a}+\mathrm{c}=1$.

Required variables used for the models for this study are described as follows:

i. $\quad$ Output-side real GDP at current PPPs (in mil. 2011US\$) denoted as CGDPO.

ii. Capital stock at current PPPs (in mil. 2011US\$) denoted as $\boldsymbol{C K}$

iii. Total factor productivity level at current PPPs (USA=1)denoted as $\boldsymbol{C T F P}$

iv. Human capital index, based on years of schooling and returns to education denoted as HC

v. Number of persons engaged (in millions) denoted as $\boldsymbol{E M P}$.

All data were sourced from the Penn World Table, version 9.0. (Feenstra, et al 2015). The sample period for the empirical analysis using time-series data was naturally conditioned by the availability of human capital stock data. For the Gambia, human capital data were not available before 1970, therefore data for our empirical analysis is from 1970 to 2016.

\section{DESCRIPTIVE STATISTICS OF VARIABLES}

The descriptive statistics for the data used in this study are presented as average growth rates, correlation coefficients and trend analysis. Table 1.0 presents the growth rate statistics and 
correlation coefficients for the data, while the trend in principal variable are presented in Figures 1 to 4 .

Table 1: Summary Statistics of Basic Data

\begin{tabular}{|l|c|c|}
\hline & $\begin{array}{c}\text { USA } \\
(\mathbf{1 9 7 0 - 2 0 1 6})\end{array}$ & $\begin{array}{c}\text { GAMBIA } \\
\mathbf{( 1 9 7 0 - 2 0 1 6 )}\end{array}$ \\
\hline Growth Rates & & \\
\hline Real GDP (Y) & 2.81 & 3.51 \\
\hline Physical Capital (K) & 3.26 & 6.05 \\
\hline Human Capital (H) & 0.45 & 0.86 \\
\hline Total Capital (K+H) & 3.26 & 6.05 \\
\hline Employed Labour (L) & 1.29 & 2.75 \\
\hline Per Capita RGDP & 1.49 & 1.06 \\
\hline Per Capita Physical Capital & 1.95 & 3.58 \\
\hline Per Capita Human Capital & -0.81 & -1.5 \\
\hline Per Capita Total Capital & 1.95 & 3.58 \\
\hline \multicolumn{2}{|l|}{} \\
\hline Correlation Coefficints & 0.99 & 0.95 \\
\hline $\boldsymbol{r}_{\boldsymbol{K} \boldsymbol{H}}$ & 0.96 & 0.98 \\
\hline $\boldsymbol{r}_{\boldsymbol{Y} \boldsymbol{H}}$ & 0.97 & 0.97 \\
\hline $\boldsymbol{r}_{\boldsymbol{Y} \boldsymbol{L}}$ & 0.95 & 0.94 \\
\hline $\boldsymbol{r}_{\boldsymbol{K} \boldsymbol{H}}$ & 0.94 & 0.97 \\
\hline $\boldsymbol{r}_{\boldsymbol{K} \boldsymbol{L}}$ & 0.98 & 0.98 \\
\hline $\boldsymbol{r}_{\boldsymbol{H} \boldsymbol{L}}$ & \multicolumn{2}{|l|}{} \\
\hline
\end{tabular}

During the period covered by this study, 1970-2016 the Gambia economy grew at 3.51 percent on the average per year in real GDP terms, with the growth of physical capital (6.05 percent), human capital ( 0.86 percent), and employment (2.27 percent) in terms of hours worked by employees. Contrasting this with the U.S. economy, GDP growth rate was 2.81 percent, physical capital grew at 3.26 percent, and human capital growth rate was 0.48 , while employment grew at 1.29 percent.

But it is to be noted in particular, the accumulation of physical capital exceeds that of human capital in the Gambia economy more than it is in the U.S. economy. That implies that with the less human capital accumulation, the physical capital may be less effective. This also lends support to the conjecture that human capital may be an important determinant for attracting effective physical capital and for achieving sustained economic growth in industrialized economies. Similarly the growth rates of per capita values were all positive except the per capita human capital which is negative. The rate is higher in the U.S economy than the Gambia economy. These results suggest a similarity between the two economies hence the test of whether Gambia economy can converge towards the U.S.A economy is justifiable.

The correlation coefficients reported in Table 1 indicate a high degree of positive correlation among the Gambia GDP, physical capital stocks, labor and human capital stocks. This can also be said of the U.S. economy. It can be seen that the correlation between human capital stocks and total capital stocks in Gambia is high (0.95) even though it has not yet reached the U.S. level of 0.99 . 
Ayeni, R. K. (2019). CAN THE GAMBIA ECONOMY CATCH-UP WITH DEVELOPED ECONOMIES IN THE LONG-RUN?: A Time-Series Test of the Convergence Hypothesis and Endogenous Growth Model with Human Capital. Archives of Business Research, 7(3), 12-26.

Figures 1 to 4 also show that RGDP and human capital experienced similar trends in the two economies between 1970 and 2016. But the magnitude of growth is higher in the U.S. than the Gambia.

Figures 1, 2, 3 and 4: TREND ANALYSIS OF RGDP AND HUMAN CAPITAL 1. Trend in Gambia Human Capital
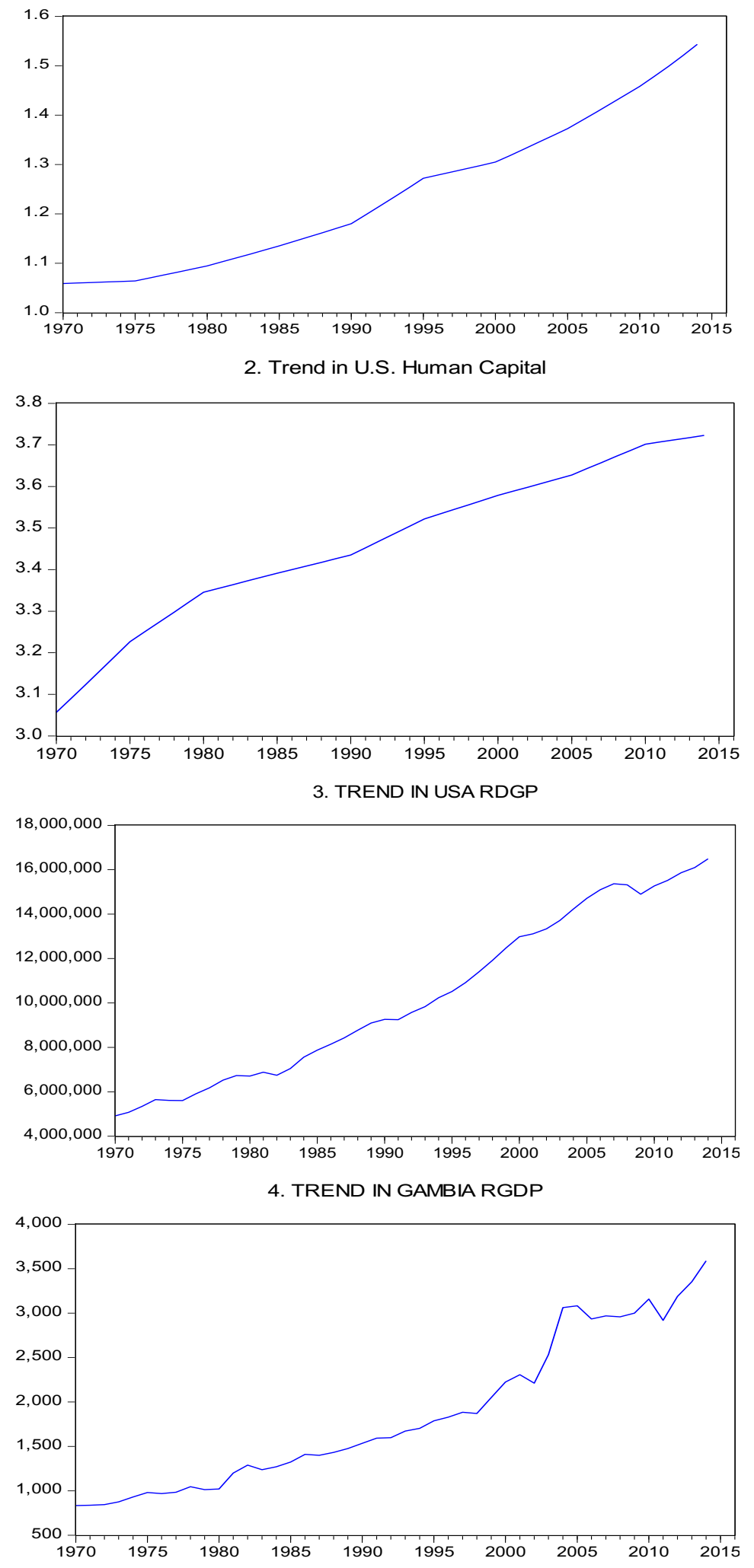


\section{EMPIRICAL ANALYSIS OF MODEL}

Equations 10, 11 and 12 were to be estimated using the OLS regression technique, but to eliminate spurious regression there is need to conduct stationarity test on the variables. The results of ADF Unit root test is reported in Table 2.

The results show that all variables, for both economies, are integrated of order one, I(1), implying that there is evidence of long run equilibrium relationship in the aggregate production function. If the raw data are used to run a classical OLS regression, it may result to a spurious regression, therefore the first difference of the data are preferred since they are all made stationary at their first difference

Table 2: Unit Root Test for Variables

\begin{tabular}{|l|c|c|c|c|c|c|c|c|}
\hline & \multicolumn{4}{|c|}{ GAMBIA } & \multicolumn{4}{c|}{ USA } \\
\hline Variable & $\begin{array}{c}\text { ADF } \\
\text { stat. }\end{array}$ & $\mathbf{5 \%}$ C. V. & prob. & Integration & $\begin{array}{c}\text { ADF } \\
\text { stat. }\end{array}$ & $\mathbf{5 \%}$ C. V. & prob. & Integration \\
\hline In(RDGP & -1.8031 & -3.5155 & 0.6862 & Nonstaionary & -2.3148 & -3.5180 & 0.4173 & Nonstaionary \\
\hline Ln(CK) & 0.3977 & -3.5180 & 0.9986 & Nonstaionary & -1.3042 & -3.5207 & 0.8732 & Nonstaionary \\
\hline EMP & -0.8207 & -4.1809 & 0.9557 & Nonstaionary & -2.2644 & -3.5180 & 0.4435 & Nonstaionary \\
\hline HC & -0.7248 & -3.5180 & 0.9646 & Nonstaionary & -3.5764 & -3.5180 & 0.0439 & Nonstaionary \\
\hline DRGDP & -5.9486 & -3.5207 & 0.0001 & $\mathrm{I}(1)$ & -4.4274 & -3.5180 & 0.0053 & $\mathrm{I}(1)$ \\
\hline DCK & -3.9778 & -3.5180 & 0.0170 & $\mathrm{I}(1)$ & -4.4625 & -3.5207 & 0.0049 & $\mathrm{I}(1)$ \\
\hline DEMP & -6.5690 & -3.5180 & 0.0000 & $\mathrm{I}(1)$ & -4.2733 & -3.5180 & 0.0080 & $\mathrm{I}(1)$ \\
\hline DHC & -6.3273 & -3.5207 & 0.0000 & $\mathrm{I}(1)$ & -6.6414 & -3.5207 & 0.0000 & $\mathrm{I}(1)$ \\
\hline
\end{tabular}

The results for regressions using the ordinary least squares estimation method on log RGDP are reported in table 3 and table 4 . Table 3 is an unrestricted version, while Table 4 is a restricted version after imposing constant returns to all factor inputs. Looking at the estimation results for The Gambia U.S. data, we find estimated coefficients of all three alternative models have the right signs conforming to a priori expectation and are all significant except for labour which is negative and not significance.

The degree of fitness is also very high for The Gambia, average of 0.96 for the three models. Gambia model shows no sign of autocorrelation for the three models. It is interesting to note that the coefficient of human capital stocks in equation (11) and the coefficient of total capital stocks in equation (12) are each highly significant.

Also the estimation results for the U.S. data, we find estimated coefficients of all three alternative models have correct signs and high significance. Physical stock, human capital stocks and labour variables are highly significant for the U.S. data, likewise the coefficient of total capital stock. (log $\mathrm{CK}+\mathrm{HC})$. 
Ayeni, R. K. (2019). CAN THE GAMBIA ECONOMY CATCH-UP WITH DEVELOPED ECONOMIES IN THE LONG-RUN?: A Time-Series Test of the Convergence Hypothesis and Endogenous Growth Model with Human Capital. Archives of Business Research, 7(3), 12-26.

Table 3: Parameter Estimates of the Cobb-Douglas Production Model: Unrestricted Estimates (Dependent Variable log GDP)

\begin{tabular}{|c|c|c|c|c|c|c|c|c|}
\hline Equation & Constant & $\log (\mathbf{c k})$ & $\log (\mathrm{hc})$ & $\log (\mathrm{ck}+\mathrm{hc})$ & $\log (\mathrm{emp})$ & $\mathbf{R}^{2}$ & DW & Autocorrelation \\
\hline \multicolumn{9}{|c|}{ THE GAMBIA (1970-2016) } \\
\hline \multirow[t]{2}{*}{10} & 3.274199 & 0.544173 & & & -0.00262 & 0.96 & 0.4081 & \\
\hline & 0.0001 & 0.0000 & & & 0.9881 & & & \\
\hline \multirow[t]{2}{*}{11} & 4.926457 & 0.238497 & 2.49183 & & -0.13408 & 0.97 & 0.4485 & \\
\hline & 0.0000 & 0.0786 & 0.0093 & & 0.4355 & & & \\
\hline \multirow[t]{2}{*}{12} & 3.274021 & & & 0.544222 & -0.00213 & 0.96 & 0.4076 & \\
\hline & 0.0001 & & & 0.0000 & 0.9903 & & & \\
\hline \multicolumn{8}{|c|}{ USA (1970-2016) } & \\
\hline \multirow[t]{2}{*}{10} & 5.650939 & 0.259344 & & & 1.254464 & 0.99 & 1.4071 & AR(1):0.9802 \\
\hline & 0.0000 & 0.0000 & & & 0.0000 & & & 0.0000 \\
\hline \multirow[t]{2}{*}{11} & 7.233361 & 0.039537 & 1.60113 & & 1.300739 & 0.99 & 1.2602 & AR(1):0.9819 \\
\hline & 0.0506 & 0.0000 & 0.0066 & & 0.0000 & & & 0.0000 \\
\hline \multirow[t]{2}{*}{12} & 2.615489 & & & 0.259344 & 1.254464 & 0.99 & 1.4071 & AR(1):0.9802 \\
\hline & 0.0000 & & & 0.0000 & 0.0000 & & & 0.0000 \\
\hline
\end{tabular}

Notes: Probability values in parentheses. Estimates for U.S were obtained with the first-order autoregressive (AR(1)) adjustment on the model. Parameter estimates of first order autocorrelation coefficients with their probability values are reported in the last column.

The degree of fitness is higher than that of the Gambia economy, 0.99 in each equation, but there is presence of mild autocorrelation in the U.S. equations. This was taken care of by using the Heteroscedasticity and Autocorrelation Consistent (HAC) Newey-West option for the specification. Also to be noted is that the coefficient of human capital stocks in equation (11) and the coefficient of total capital stocks in equation (12) are significant at 0.01 levels for the U.S. data.

\section{TESTING THE CONVERGENCE HYPOTHESIS}

1. Convergence hypothesis implied by the conventional neoclassical growth model. That is $(\boldsymbol{\alpha}+\boldsymbol{\beta}=1)$ Constant Returns to Scale.

Table 3a: Returns to Physical Capital and Labour

\begin{tabular}{|l|l|c|c|c|c|}
\hline Country & Equation & $\boldsymbol{\alpha}$ & $\mathbf{B}$ & $\boldsymbol{\alpha}+\boldsymbol{\beta}$ & Remark \\
\hline Gambia & 10 & 0.544173 & $\mathbf{- 0 . 0 0 2 6 2}$ & $\mathbf{0 . 5 4 1 5 5 3}$ & $\boldsymbol{\alpha}+\boldsymbol{\beta}<1$ \\
\hline U.S. & 10 & 0.259344 & 1.254464 & $\mathbf{1 . 5 1 3 8 0 8}$ & $\boldsymbol{\alpha}+\boldsymbol{\beta}>1$ \\
\hline
\end{tabular}

2. Statistical significance of the coefficient of human capital stocks $(\boldsymbol{H})$, and the hypothesis of constant returns to capital $(\alpha+c=1)$. 
Table 3b: Returns to Physical and Human Capital

\begin{tabular}{|c|c|c|c|c|c|c|}
\hline Country & Equation & Human Capital & A & C & $\boldsymbol{\alpha + c}$ & Remark \\
\hline Gambia & 11 & Significant & 0.238497 & 2.491837 & 2.730334 & $\alpha+>1$ \\
\hline U.S. & 11 & Significant & 0.039537 & 1.60113 & 1.640667 & $\alpha+c>1$ \\
\hline
\end{tabular}

The U.S. economy and The Gambia economy both experience increasing returns to Human Capital.

3. Hypothesis of Constant Returns to Total Capital $(\boldsymbol{a}+\mathrm{c}=1)$ from the estimation result of equation 12.

Table 3c: Returns to Total Capital

\begin{tabular}{|c|c|c|c|c|c|}
\hline Country & Equation & $\boldsymbol{\alpha}$ & $\mathbf{C}$ & $\boldsymbol{\alpha + c}$ & Remark \\
\hline Gambia & 12 & & & $\mathbf{0 . 5 4 1 5 5 3}$ & $\boldsymbol{\alpha}+\boldsymbol{c}<\mathbf{1}$ \\
\hline U.S. & 12 & & & 0.259344 & $\boldsymbol{\alpha}+\boldsymbol{c}<\mathbf{1}$ \\
\hline
\end{tabular}

If the hypothesis of constant returns to capital $(\boldsymbol{a}+\boldsymbol{c}=1)$ is accepted from the estimation results of equations 11 and 12, it may be necessary to re-estimate equations 11 and 12 by imposing the linear constraint $\boldsymbol{a}+\mathrm{c}=1$. But the analyses above show that hypothesis of constant returns is rejected for equations 11 and 12, for the two countries. A test of increasing return hypothesis on each country is shown below:

Table 3d: Returns to Scale

\begin{tabular}{|c|c|c|c|c|c|c|}
\hline Country & Equation & $\boldsymbol{\alpha}$ & $\mathbf{B}$ & $\mathbf{C}$ & $\boldsymbol{\alpha + \boldsymbol { \beta } + \mathbf { c }}$ & Remark \\
\hline Gambia & 11 & 0.238497 & -0.13408 & 2.491837 & 2.5963 & Increasing returns \\
\hline U.S. & 11 & 0.039537 & 1.300739 & 1.60113 & 2.9414 & Increasing returns \\
\hline
\end{tabular}

Since increasing returns to all factors $(\boldsymbol{\alpha}+\boldsymbol{\beta}+c>1)$ is accepted for all two countries, it is necessary to impose the restriction of constant returns to scale (CRS) and re-estimate the three equations using the per capita variables. The results of this are reported in table 4 . 
Ayeni, R. K. (2019). CAN THE GAMBIA ECONOMY CATCH-UP WITH DEVELOPED ECONOMIES IN THE LONG-RUN?: A Time-Series Test of the Convergence Hypothesis and Endogenous Growth Model with Human Capital. Archives of Business Research, 7(3), 12-26.

Table 4: Parameter Estimates of the Cobb-Douglas Production Model: Constant Return to Scale Restricted Estimates (Dependent Variable $\log \frac{r g d p}{e m p}$ )

\begin{tabular}{|c|c|c|c|c|c|c|c|}
\hline Equation & Constant & $\log \frac{c k}{e m p}$ & $\log \frac{h c}{e m p}$ & $\log \frac{c k+h c}{e m p}$ & $\mathbf{R}^{2}$ & DW & $\begin{array}{c}\text { Auto } \\
\text { correlation }\end{array}$ \\
\hline \multicolumn{8}{|c|}{ THE GAMBIA (1970-2016) } \\
\hline \multirow[t]{2}{*}{10} & 5.3305 & 0.3719 & & & 0.85 & 1.65 & $\operatorname{AR}(1): 0.7885$ \\
\hline & $(0.0000)$ & $(0.0000)$ & & & $(0.00)$ & & $(0.0000)$ \\
\hline \multirow[t]{2}{*}{11} & 4.4081 & 0.4062 & 0.4443 & & 0.89 & 1.70 & AR(1):0.802641 \\
\hline & $(0.0000)$ & $(0.0000)$ & $(0.0808)$ & & $(0.00)$ & & $(0.0000)$ \\
\hline \multirow[t]{2}{*}{12} & 7.7266 & & & 0.1188 & 0.80 & 1.61 & AR(1):0.792172 \\
\hline & $(0.0000)$ & & & $(0.0619)$ & $(0.00)$ & & $(0.0000)$ \\
\hline \multicolumn{7}{|c|}{ USA (1970-2016) } & \\
\hline \multirow[t]{2}{*}{10} & 6.686684 & 0.37262 & & & 0.99 & 1.323 & AR(1):0.994595 \\
\hline & $(0.0000)$ & $(0.0036)$ & & & $(0.000)$ & & $(0.0000)$ \\
\hline \multirow[t]{2}{*}{11} & 5.349347 & 0.337448 & 0.504115 & & 0.99 & 1.421 & AR(1):0.984912 \\
\hline & $(0.0001)$ & $(0.0003)$ & $(0.0025)$ & & $(0.000)$ & & $(0.0000)$ \\
\hline \multirow[t]{2}{*}{12} & 5.006693 & & & 0.367458 & 0.995 & 1.426 & AR(1):0.976345 \\
\hline & $(0.0001)$ & & & $(0.0000)$ & $(0.000)$ & & $(0.0000)$ \\
\hline
\end{tabular}

Notes: Probability values in parentheses. Estimates for U.S and Gambia were obtained with the first-order autoregressive (AR(1)) adjustment on the model. Parameter estimates of first order autocorrelation coefficients with their probability values are reported in the last column.

Under the CRS restriction in Table 5, the coefficient of per capita human capital is less than 1 for The Gambia (0.4443) and quite insignificant at 0.05 level. The estimated capital coefficient is not too high with $a=0.3719$ in equation (10) and $a+c=0.8505$ in equation (11). Both results reject the null hypothesis of constant returns to capital ( $a=1$ or $a+c=1)$, It can also be seen that Gambia economy do show near constant returns to capital (0.8505) in equation 11 . The U.S. data also show near constant return to capital in equation $11 a+c=0.841563$ In particular, when we define capital as combination of physical and human capital by equation (11), but not as direct Total capital. The estimated capital coefficient ( 0.12 for Gambia) which is insignificant and rejects the null hypothesis $(a+c=1)$. Whereas the U.S. economy has a significant returns to Total per capita even though diminishing returns.

The above results partly support the hypothesis of constant returns to a broad concept of capital that includes human capital. This supports this concept of capital advanced by the recent models of endogenous economic growth. Barro and Salai-Martin (1992). In their findings, according to Neoclassical model a coefficient value of 0.8 is required for a broadly defined concept of capital to fit the observed speeds of convergence from the 98-country group data. The estimated coefficient of broadly defined capital for the Gambia and United States is consistent with their conjecture. Inferences from the findings of this study are the following:

1. Gambia economy on the average grows faster (3.51) than the U.S. economy (2.58), this lend credence to the Neoclassical growth model that countries with lower GDP per capital will tend to grow faster than Richer ones, but convergence is not always implied.

2. The accumulation of physical capital exceeds that of human capital in the Gambia economy more than it is in the U.S. economy. 
3. Growth of per capita human capita is low in the Gambia, making labour to be insignificant.

4. There is increasing returns to capital in the Gambia meaning that if Gambia improves on Human Capital Development, the economy tends to grow faster and better.

5. It was revealed that Gambia economy shows near constant returns to capital (0.8505) in the Human Capital equation. That is when we define capital as combination of physical and human capital by equation but not as direct Total capital.

6. The U.S. data also show near constant return to capital in the same equation.

\section{THE ROLE OF HUMAN CAPITAL AND THE CONVERGENCE HYPOTHESIS}

The results of the Cobb-Douglas production function in level form using time-series data for the United States and Gambia reveal quite results different from those using cross-country data. Human capital is found to be a significant factor in aggregate production in the Gambia economy. It complements both physical capital and labor, and therefore, income growth cannot be explained by physical capital and labor only. Labor on its own was found to be ineffective in the absence of knowledge.

Kyriacou (1991) and Benhabib and Spiegel(1992) reported negative coefficients for the growth of human capital but a positive significant coefficient for the initial level of human capital stocks.

Their explanation of the result is that there could be high fixed costs in the production of human capital stocks, high opportunity costs for acquiring education in countries with low per capita human capital, and transaction, interaction, communication, and other costs when educated workers have to operate in a poorly educated environment.

Now, if we accept their interpretation, it implies that a developing economy can converge, or catch up, only after a certain level of human capital is endowed or created. The difference in the magnitude of estimated capital coefficients between the U.S. data and the Gambia data lends credence to this assertion. The diminishing returns to capital estimated for South Korea implies that Korea started from a lower level of capital, and therefore, with a higher rate of return prevailing, the growth rate of capital has been higher. Convergence or catch-up can occur in the lonr-run, but accumulation of human capital is found to be an important determinant of the growth of the Gambia economy, hence the convergence. The estimated near constant returns to broadly defined capital from the US. data indicates that the U.S. economy has passed the threshold, while The Gambia economy has not yet, and is already at a steady state.

In summary, convergence will be observed for developing economies which make use of human capital as a productive input. On the other hand, divergence will be observed between developing economies which could not make use of human capital as a productive input and developed economies which enjoy an economy-wide externality from accumulated human capital stocks.

As pointed out by the former Governor of Nigeria Central Bank, (Sanusi Lamido) the growth miracle of countries like South Korea is not a "miracle" but the result of sustained accumulation and use of human capital which is lacking in many African countries. His words, and findings from this study, implies that until a converging economy's human capital reaches a certain threshold point, the externality implied by endogenous growth models cannot be expected. Until that stage, human capital will serve as a productive input rather than as a source of externality. 


\section{THE GAMBIA PER FINDINGS AND THE CONVERGENCE HYPOTHESIS}

The World Bank sponsored research on education sector, public expenditure review of the Gambia in 2017 gave the following summary of education outlook in The Gambia and their recommendations follow the findings of the convergence hypothesis tests in this study.

1. The Gambia has faced several significant socioeconomic and political challenges over the past few years, from droughts in 2011 and 2014 to the Ebola-related crisis in 2014 and, more recently, political unrest during the 2016 presidential election.

2. The country also faces significant development challenges as reflected by its low human development country ranking on the Human Development Index (HDI) in 2015 (173 out of 188 countries), which is driven mainly by its low healthand education outcomes.

3. The Ministry of Basic and Secondary Education (MoBSE) has benefited from a consistent and strong management team during the past several years, which has been critical in addressing demographic and other socioeconomic challenges listed earlier. The government has made significant efforts to increase enrollment numbers at all levels of education, even in the face of rapid population growth. However, despite the government's commitment to education, the sector performance tends to be low.

4. Lower basic school (LBS) (grades 1-6). Access rates to primary education stagnated between 2010 and 2015, with the GER marginally decreasing from 90 percent to 87 percent, although the actual number of students enrolled increased from 228,495 to 308,729 (a 35 percent increase) during the same time. Access tends to be lower in rural areas (79 percent) and among the poorest households (73 percent). It is also lower than the SSA average that stands at 102 percent.

5. Upper basic school (UBS) (grades 7-9) and senior secondary school (SSS) (grades 1012).Access rates in secondary education are low, with the GERs of 62 percent and 44 percent in UBS and SSS, respectively-both lower than the SSA average of 71 percent and 47 percent, respectively.

6. Postsecondary education. Access to higher education remains limited in The Gambia and is lower than the SSA average of 10 percent. Although there was a slight increase of 1.5 percent between 2010 and 2015, it currently stands at 6.5 percent. This level of education registers the largest disparities across equity dimensions.

7. The education sector is funded in large part by private households that contributed about 58 percent of total spending in education in 2015, followed by the public sector, which accounted for 34 percent. The sector also relies heavily on donor contributions that were equivalent to more than 20 percent of non-household spending in 2015.

8. total education spending as a share of gross domestic product (GDP) has steadily increased from 2.6 percent in 2010 to 3.2 percent in 2015 , although this allocation remains below the best practices benchmark of allocating 4-6 percent of GDP.

9. Projections of the cost of education reveal that increasing access has significant implications on the government's fiscal space and the government is unlikely to mobilize resources needed to achieve the desired level of access.

10. The government underutilizes teachers at all levels of education as the average studentteacher ratio (STR) is 28 at ECD, 33 at primary, 28 at lower secondary, and 27 at upper secondary (excluding teacher trainees).

\section{CONCLUSION}

The paper first estimated three Cobb-Douglas specifications of an aggregate production function suggested by the endogenous growth model with human capital. Instead of using cross-country growth data with proxy variables for human capital, the direct estimates of human capital stocks for the United States and Gambia are used for regression. The estimation 
results in level form confirm the proposition that human capital plays a significant role in economic growth.

As the major aim of the paper is to provide a theoretical and empirical justification for the quick and steady implementation of the recommendations of the education sector public expenditure report, it is pertinent here to summarize the recommendations.

The main findings from the PER were grouped under four areas for policy recommendations:

(a) Adopting measures to improve internal efficiency of the education sector to cope with the limited fiscal space in the short run and ensure the adequacy and sustainability of public spending;

(b) Ensuring public resources serve to improve equity through relevant intervention instruments;

(c) Improving capacity building to better evaluate service delivery, learning outcomes, and foster a resilient education system; and

(d) Improving the human capital development of the labor force through adequate provision of second chance education programs and raising the educational attainment among those who may have failed to complete their studies or who have never been to school.

Linking this with the findings of this study, Gambia economy has the tendency of "catch-up" with developed economy under the condition of improved and sustained human capital development. To achieve this, the education budget should be increased in the medium to long term. As it currently stands, public investment in education in The Gambia is at 3.2 percent of GDP compared with the recommended level of 4-6 percent and the Sub-Saharan Africa (SSA) average of 4.6 percent, which is far below the levels recommended to effectuate any real change to the sector. The Gambia economy lacks enough qualified personnel at the tertiary institutions.

Presently the Gambia enjoys external supports to their human capital development in form of technical aids from countries like Nigeria, Cuba, etc. the country can intensify on these foreign aids to train personnel for effectiveness of labor. When knowledge enters labor, it becomes effective labor; output tends to increase over time

\section{References}

Ayeni, R. K. (2018), Knowledge Capital, Human Capital Stocks and the Growth of Africa Economies: A Panel Data Analysis IOSR Journal of Economics and Finance (IOSR-JEF) 2321-5925. 9 (3) (May - June 2018), PP 53-63 www.iosrjournals.org

Barro, R. J. (1991), Economic growth in a cross section of countries. Quarterly Journal of Economics 56: 407-43.

Benhabib, J. and M. M. Spiegel. (1992), Growth accounting with physical and human capital accumulation. C. V. Starr Center Working Paper no. 91-66. New York University.

Feenstra, R. C., Robert I. and M. P. Timmer (2015), "The Next Generation of the Penn World Table" American Economic Review, 105(10), 3150-3182, available for download at www.ggdc.net/pwt

Kyriacou, G. (1991). Level and growth effects of human capital. C. V. Starr Center Working Paper no. 91-26. New York University.

Lucas, R. (1988). On the mechanics of economic development. Journal of Monetary Economics 22: 3-42.

Pyo, H. K. (1995), A Time-Series Test of the Endogenous Growth Model with Human Capital, a selection from an out-of-print volume from the National Bureau of Economic Research http://www.nber.org/books/ito_95-2 (p. $229-245)$

Rebelo, S. (1991). Long-run policy analysis and long-run growth. Journal of Political Economy 99: 500-21.

Romer, P. (1986). Increasing returns and long-run growth. Journal of Political Economy, (94), pp 1002-37 
Ayeni, R. K. (2019). CAN THE GAMBIA ECONOMY CATCH-UP WITH DEVELOPED ECONOMIES IN THE LONG-RUN?: A Time-Series Test of the Convergence Hypothesis and Endogenous Growth Model with Human Capital. Archives of Business Research, 7(3), 12-26.

Romer, P. (1990). Endogenous technological change. Journal of Political Economy (98): S71-S102

Solow, Robert M. (1956). A contribution to the theory of economic growth. Quarterly Journal of Economics 70 : 65-94.

Stokey, Nancy L. (1991). Human capital, product quality and growth. Quarterly Journal of Economics 106: 587616.

Tamura, R. (1991). Income convergence in an endogenous growth model. Journal of Political Economy 99: 52240.

World Bank Report (2017), “The Gambia: Education Sector Public Expenditure Review” An Efficiency, Effectiveness, Equity, Adequacy, and Sustainability Analysis Report No. ACS23503 